\title{
A SUSTENTABILIDADE DO DESENVOLVIMENTO ECONÔMICO GLOBAL: O PROCESSO PARTICIPATIVO DOS PAÍSES RICOS NA ASSISTÊNCIA AOS PAÍSES POBRES DIANTE DE UM POSSÍVEL PACTO DE COMBATE À POBREZA
}

\section{SUSTAINABILITY GLOBAL ECONOMIC DEVELOPMENT: THE PARTICIPATORY PROCESS OF RICH COUNTRIES IN ASSISTANCE TO POOR COUNTRIES BEFORE A POSSIBLE PACT TO COMBAT POVERTY}

\author{
Anne Augusta Alencar Leite Reinaldo \\ Belinda Pereira da Cunha ${ }^{2}$
}

\section{RESUMO}

Este artigo tem por objeto a análise da sustentabilidade do desenvolvimento econômico global no que concerne à assistência fornecida pelos países ricos aos países pobres na conjuntura moderna, enfocando como seria um possível pacto global pelo direito ao desenvolvimento, sendo construído na plataforma da sustentabilidade do desenvolvimento e sob a égide do estudo da conceituação e da evolução da exclusão social e da pobreza.

Palavras-chave: Direito humano, Desenvolvimento econômico, Sustentabilidade, Pobreza

\begin{abstract}
This article aims at the analysis of the sustainability global economic development with regard to the assistance provided by rich countries to the poor countries in the modern environment, focusing on how it would be possible global agreement for the right to development, being built on the sustainability of development platform and under the aegis of the study of the concept and the evolution of social exclusion and poverty.
\end{abstract}

Keywords/ : Human rights, Economic development,Sustainability, Poverty

\footnotetext{
${ }^{1}$ Doutoranda em Direitos Humanos e Desenvolvimento pela UFPB, Universidade Federal de Paraíba, PB, Brasil. E-mail:

${ }^{2}$ Doutorado em Direito pela pontifícia Universidade Católica de São Paulo, PUC/SP, Brasil. E-mail:
} 


\section{INTRODUÇÃO}

A exclusão social e a pobreza não guardam idêntica correlação. Mesmo diante de fatos geradores similares que ensejam no aparecimento destes fenômenos sociais, seus desdobramentos são, na maioria das vezes, diferenciados e em escalas alarmantes na conjuntura moderna. Antes se preocupava apenas com a inserção social e com os consequentes meios de inclusão dos excluídos do mercado de trabalho; atualmente, a pobreza passa a configurar uma das preocupações mundiais e, em conjunto com a exclusão social, passam a ser alvos da busca incessante do Estado na efetivação dos direitos de/ ao desenvolvimento.

A globalização como fenômeno do processo de internacionalização das economias capitalistas, é responsável pelo novo paradigma de consumo e, consequentemente, por uma nova conceituação da exclusão social, principalmente no que se refere à sensação de exclusão social, visto que, dependendo do nível de desenvolvimento do país, esta sensação, bem como a própria exclusão, aufere patamar minorado ou majorado.

O conceito de ambos os institutos é multidisciplinar, sendo influenciado por questões sociológicas, econômicas, dentre tantas outras áreas responsáveis pela plataforma de construção da conceituação de pobreza e exclusão social.

A dificuldade de encontrar formas de inserção social na era Moderna é, dentre tantas outras causas, a maior responsável pela emergente necessidade de reconstrução do Estado, tendo em vista que, na busca do combate à pobreza e à exclusão social, a efetivação da cidadania, sendo esta, o direito a ter direitos, obrigações e a consequente inserção social, configura a plenitude dos direitos humanos, bem como a concretude do direito humano ao desenvolvimento.

Nesse contexto percebe-se que a assistência ao desenvolvimento dos países pobres emerge, urgentemente, a realização de ações coordenadas dos países ricos, bem como dos próprios pobres, refletindo na efetivação e concretização dos Direitos ao desenvolvimento e do desenvolvimento, por meio de um pacto global pelo Direito ao desenvolvimento. 


\section{A POBREZA E A EXCLUSÃO SOCIAL: JUSTIFICATIVAS INERENTES AODESENVOLVIMENTO ECONÔMICO SUSTENTÁVEL NA MODERNIDADE}

A globalização configura o processo de internacionalização das economias capitalistas; nesse contexto, necessário é diferenciar a sensação de exclusão social da exclusão social no modelo econômico capitalista, visto que o fenômeno da globalização mantém relações intrínsecas com a evolução da exclusão social na Modernidade.

Importa pontuar algumas diferenças entre o termo exclusão e outros aparentemente correlatos, como exploração, pobreza e desigualdade, espécies que guardam entre si diferenças e semelhanças.

Zaffaroni afirma que estar excluído não significa ser explorado. Para ele, "ser explorado é uma dialética; sem explorador, não existe explorado", porém, "o incluído não precisa do excluído", assim, o excluído seria alguém "fora do sistema produtivo, que perturba, que está demais, que nasceu errado, descartável" "estar excluído não significa ser explorado.” (FEITOSA, 2013)

$\mathrm{Na}$ conjuntura atual do capitalismo e do modelo econômico do liberalismo, do consequente declínio do Estado do Bem-Estar Social e do crescimento das empresas transnacionais, percebe-se que a precarização e a diferenciação nas relações de trabalho geram os fenômenos da exclusão e desigualdades sociais (exército de excluídos) em uma proporção jamais visualizada na História, isto porque, na conjuntura Moderna há maior exploração e, consequentemente, maior exclusão.

O sentimento de desamparo que emerge na Era Moderna é percebido e notado quando o Estado reestrutura a sua função e passa a deter a preocupação com o novo fenômeno da exclusão social. (DUPAS, 2005)

Nesse contexto, atrelada ao fenômeno da globalização, o consumismo fundado no modo de vida das sociedades ocidentais aponta para a crescente conjuntura do sentimento de desamparo, posto que quem não consome na proporção da sociedade ocidental, sente-se desamparado não só pela sociedade, mas pelo Estado que não tutela eficazmente o fenômeno da exclusão social. É o que se constata dos ensinamentos de Maria Luiza Feitosa: 


\begin{abstract}
A precarização e a diferenciação nas relações de trabalho representam fatores que, aliados à crise do Estado de Bem-Estar, especialmente na chamada periferia do mundo capitalista, levaram à enorme exclusão e a desigualdades sociais. Mais do que explorados, este processo começou a gerar um exército de excluídos, entes vulneráveis que sequer conseguem pertencer ao mercado de consumidores. (FEITOSA, p.106, 2013)
\end{abstract}

Percebe-se que há uma anedota latino-americana quando da projeção do consumo da sociedade ocidental; essa anedota contada por Wolfe e referida em Dupas, caricatura a sociedade consumidora dos países periféricos seccionada em três grupos: a)detentores de cartões de crédito; b)os que não possuem, mas gostariam de possuir; c) os que nunca sequer ouviram falar em cartão de crédito. (FEITOSA, 2013)

\begin{abstract}
Há autores que enfatizam a compreensão de que o capitalismo, ao suscitar a racionalidade acumulativa e individualista, instigadora de competição entre os agentes, teria concebido a categoria do "outro" como alguém a ser vencido, em processo de hiperobjetivação do mundo [...] Para Dupas, o atual padrão de acumulação do capital, aliado à revolução tecnológica, teria mudado o conceito de ocupação, trazendo novos e piores parâmetros para as relações de emprego - quais sejam,flexibilidade, precariedade, instabilidade, entre outros. Segundo Martins, a sociedade capitalista "exclui para incluir, mas incluir de outro modo, segundo suas próprias regras", seguindo sua própria lógica (Martins, 2007, p. 32) (FEITOSA, p.106,107, 2013)
\end{abstract}

Nesse diapasão, a sociedade contemporânea passa a consumir como parte da realização social e pessoal, elevando, assim, o sentimento de exclusão relativizado da Era Moderna: necessidades básicas passam a configuram o "ter" material. A satisfação de vida passa a ser medida pelo "ter" e não pelo "ser", aumentando, consequentemente, não mais a sensação de exclusão social atual, mas a própria exclusão social da Modernidade.

Com a globalização, ante o agravamento da desigualdade, o tema da exclusão social se dissemina em análises interdisciplinares, abrangendo questões econômicas, políticas, sociológicas, antropológicas, psicológicas etc., e impactando as concep-ções de integração social e/ou de ordem social [...]Atente-se, pois, que a abordagem da exclusão, além de transversal, é multidimensional e multinível. Segundo Gerry Rodgers, abrange o acesso a bens e serviços, assim como engloba questões de segurança, justiça e cidadania, podendo representar desde a exclusão do mercado de trabalho (desemprego) à exclusão do trabalho regular (trabalho precário e parcial) ou mesmo à exclusão no mercado de trabalho (diferença entre empregos ruins, de maior oferta, e empregos bons, de maiores exigências), tudo isto em um quadro que pode mudar de acordo com critérios como raça, gênero, idade etc. (FEITOSA, p.108, 2013)

Nesse sentido, importa ressaltar a conceituação de Guarry Rogers sobre os "velhos e novos excluídos". Os "velhos excluídos" são aqueles que sempre viveram em situação de exploração, suportando formas diversas de colonização (terceiro mundo e periferia), noutro norte, os "novos excluídos" são os grupos até recentemente 
integrados, mas marginalizados do padrão de desenvolvimento considerado ideal em razão de guerras ou crises econômicas. (SACHS, 2005)

Por esta razão, no contexto da distinção entre aqueles que historicamente configuram como excluídos e os recentemente incluídos na exclusão social é que se percebe a real preocupação com o fenômeno da exclusão: antes da exclusão moderna, preocupavase, tanto o Estado como a sociedade, com as condições de exploração na qual

a exploração se dava; no contexto moderno, tal preocupação também apresenta roupagem moderna: a maior dificuldade de encontrar formas de inserção social vence a então preocupação com as condições da exploração, assim, atualmente, inserir na sociedade o excluído é o papel capital das políticas públicas sociais do Estado Moderno. É o que se extrai dos ensinamentos da Doutrina Moderna:

Para aqueles Estados cujos governos abraçam orientação social, importa adotar as necessárias políticas públicas de inclusão, nos mais variados campos; para o mercado e para a sociedade civil, os mecanismos da inclusão passam pela instrumentalização de recursos econômicos e humanos, a serem repassados ao Estado sob a forma de contribuição. Há que se pensar aqui na substituição de valores econômicos meramente estéticos ou matemáticos por valores sociais éticos, que abrangem a responsabilização dos agentes na urgente tarefa de promoção da igualdade social e da proteção dos vulneráveis. (FEITOSA, p. 109, 2013)

A exclusão social é percebida em diferentes níveis, quais sejam: exclusão do mercado de trabalho, do trabalho regular, do acesso a moradias decentes e a serviços comunitários, do acesso a bens e serviços, dentro do mercado de trabalho, da possibilidade de garantir a sobrevivência do acesso à terra e dos direitos humanos. Todos esse níveis configuram uma das facetas do fenômeno da exclusão social e exemplificam a conceituação interdisciplinar do mesmo e o posicionamento estatal na busca da inserção:

Diante da abrangência desse quadro teórico e conceitual, cabe reconhecer que a questão da exclusão ficou tão expandida e complexa, que hoje não se luta mais contra a exploração imposta pelas condições exaurientes do trabalho, como ocorreu no período do fordismo. Na atualidade, muitos sustentam que o impacto das estruturas globalizantes teria obrigado, em definitivo, os Estados a adotarem fórmulas capazes de garantir alguma inserção no trabalho, ainda que ao custo da perda de garantias constitucionais, conformando-se estoicamente com a ideia de perder os anéis para não ficar sem os dedos. (FEITOSA, p.108, 2013)

O tipo de desenvolvimento reflete no nível da exclusão social. No terceiro mundo e na periferia internacional, o modelo de crescimento pautado e construído na dependência emerge e desemboca nas teorias dos modelos de desenvolvimento Furtadiana. 
A exclusão pode ainda estar vinculada ao tipo de desenvolvimento adotado pelo país, sabendo-se que não se trata, no caso dos países periféricos, de uma opção. Neste ponto, no Brasil, cabe destacar a dimensão histórica e estrutural da exclusão, gerada pela divisão social de trabalho e pelos processos de exploração capitalistas. É a dupla crise da periferia, a qual se refere Furtado: a da própria civilização industrial, oriunda da racionalidade instrumental exauriente e a crise específicadas economias periféricas, em razão da dependência (Furtado, 2002, p. 68).

Aliado ao modelo de desenvolvimento e diante do reflexo do uso do termo multidisciplinar, exclusão social " [...] significa desde estar excluído da possibilidade de garantir a sobrevivência física, até um sentimento subjetivo de ressentimento por não desfrutar de bens, capacidades ou oportunidades que outros indivíduos desfrutam." (Dupas, in FEITOSA, p.108, 2013)

A sensação de exclusão apresenta-se diferente nos países centrais e nos periféricos, não obstante as fontes serem idênticas percebe-se que o grau efetivo é diferente. A plataforma de construção multidisciplinar da exclusão social é responsável pela origem idêntica e pelos reflexos divergentes.

Quando da análise da exclusão social num quadro comparativo entre os países ricos e os pobres, Dupas leciona com perfeição que aquele conceito diferencia-se da pobreza:

\begin{abstract}
A existência nos países mais ricos de mecanismos públicos de bem-estar social, faz que o conceito de exclusão relevante para eles possa ser, em alguma medida, descolado daquele de pobreza, o que não me parece pertinente no caso dos países nos quais os cidadãos não dispõem dessa rede de proteção. (DUPAS, in FEITOSA, p.110, 2013)
\end{abstract}

Nesse contexto, diante da evolução do conceito de exclusão social, importa destacar a fundamental importância do conceito de pobreza no estudo do fenômeno da exclusão social. É o que se percebe quando da recente preocupação com a desigualdade e a pobreza no mundo Moderno:

Nesse ponto da análise, outra assertiva se impõe: o fato de sempre ter havido exclusão, mas de ser recente a preocupação com a desigualdade e a pobreza. Martins, ao pontuar que o capitalismo gera excluídos e incluídos segundo sua lógica egoística, assevera que quem está incluído pelo capital pode estar sendo desenraizado de sua condição humana, do sentimento de solidariedade e respeito para com o outro (Martins, 2007, p. 34). Nos países subdesenvolvidos, chamados anteriormente de terceiro mundo, surgiram os esquemas de facilitação, clientelismo, favorecimentos e corrupção; aqui, não há que se falar em inclusão/exclusão de minorias, vez que excluídos são a maioria, ou, do ponto de vista dos incluídos, simplesmente os "outros". Esta racionalidade despolitizada teria afastado, especialmente no con-texto da periferia, a possibilidade da programação política do desenvolvimento includente e plural, única maneira de materializar, em prol de todos, o conceito de desenvolvimento que interessa ao conjunto do país. (FEITOSA, p.109, 2013) 
O foco da definição de exclusão social em países periféricos é divergente do apresentado nos países desenvolvidos. A face fundamental da exclusão é percebida quando da real incapacidade de satisfazer necessidades básicas, que não é o sentimento gerado pela exclusão social nos países ricos e desenvolvidos.

A aferição de políticas públicas para a redução das desigualdades se baseia em mecanismos de averiguação da pobreza. É nesse contexto que o estudo intitulado de "Linhas de pobreza" de Amartya Sen se faz salutar na tentativa de entender a real diferença entre pobreza absoluta e relativa. Absoluta seria a que expressa a não satisfação de um conjunto de necessidades básicas, o "mínimo vital"; a relativa se configuraquando se compara uma camada que alcançou patamar mínimo de sobrevivência a estratos de maior renda e bem-estar com a dimensão da desigualdade, adotando como referência o padrão de riqueza alcançado.

O conteúdo da linha de pobreza está intrinsecamente relacionado ao grau de arbitrariedade estabelecido na sociedade, visto que a definição de pobreza que terá efetividade será a que a sociedade considera razoável, diante das dimensões conceituais, culturais e políticas.

Os pobres, conforme as "linhas de pobreza" são aqueles em que a renda não atinge exatamente a indicada pela linha de pobreza. Após identificação da linha de pobreza, o cálculo do quociente entre o número de pobres e a população total (índice impróprio) deve ser levantado e observado que, o que não contempla a distribuição de renda entre os mais pobres, falseia o tipo de políticas que deveriam ser assumidas para combater a pobreza.

"A pobreza deve ser definida a partir da variabilidade interpessoal na conexão entre renda e capacidades [...]" “[...] a igualdade de oportunidades passa por uma igualdade de capacidades.” (SEN; KLIKSBERG, p. 109, 2010)

A pobreza não é uma questão de escassez de bem-estar senão de incapacidade para conseguir bem-estar precisamente pela ausência de meios. A necessidade de reconstruir o Estado, a transformação no welfare, a ideia de que não há direitos sem responsabilidades, o desenvolvimento alternativo e a estrutura política radical utópica, bem como a solidariedade intergeracional são meios capazes de "ajuda para auto ajuda".

A capacidade do combate à pobreza é percebida quando as políticas públicas passam a constituir instrumentos de efetivação e concretização dos direitos 
socioeconômicos e na busca do pleno desenvolvimento, não sendo permitido que tais medidas e ações sejam mecanismos que impetrem na opinião pública o engessamento da ação estatal. (MESTRINER, 2001)

\begin{abstract}
Assim, a análise da pobreza precisa adotar, além da perspectiva econômica, aspectos políticos e sociais. Para MeghnadDesai (1995), é igualmente importantetratar a questão da pobreza como conceito social subjetivo, que engloba inclusive a disposição dos não pobres em transferir renda aos mais pobres de sua sociedade e os mecanismos de realização desta meta. (FEITOSA, p.110,02013)
\end{abstract}

O desenvolvimento econômico permeia a atuação estatal, assim sendo, a assistência social se apresenta como uma das mais variadas formas de intervenção do Estado no direito ao desenvolvimento (TRINDADE, 2002). Partindo da concepção de João Bosco Leopoldino da Fonseca (2010) de que o desenvolvimento econômico abrange uma esfera qualitativa e não quantitativa como o crescimento econômico - num contexto social dos direitos humanos - evidencia-se a intrínseca importância da juridicidade das políticas públicas assistenciais na busca constante do desenvolvimento, tendo em vista o número cada vez maior de pessoas que vivem em condições subumanas de extrema hipossuficiência socioeconômica e á margem do desenvolvimento.

Importa ressaltar que, historicamente, no Brasil, medidas e ações governamentais de caráter assistencial sofrem críticas da opinião pública e inserem-se em contextos políticos desprovidos de legitimidade jurídica (SPOSATI, 2005).

\begin{abstract}
No Brasil, programas de transferência direta de rendas, como o Bolsa Família (Lei no 10.836/2004), por exemplo, provocam a revolta da classe média, sob o dis-curso de que a transitoriedade e a gratuidade da ajuda, embora reduzam a pobreza,criam, na verdade, uma geração de cidadãos desocupados e preguiçosos. O ranço contra a inclusão diz muito da ignorância de uma sociedade que se programou para ser servida, usufruindo entre seus pares o bem-estar produzindo pelo conjuntosocial. Ao deixar de incluir e qualificar maciçamente a mão de obra nacional, o país hoje padece da ameaça de desindustrialização e da perda geral de conquistas, o que acabará afetando a todos.
\end{abstract}

Cumpre destacar que a cultura dos excluídos pode configurar como sendo mais rica do que aquela do consumismo dos ricos, quando se percebe que o desamparo estatal, por meio das falhas das políticas públicas, sociais ou não, e a crescente violência da periferia passam a ser realidades vividas e, infelizmente aceitáveis na era moderna.

Entretanto, o princípio da solidariedade humana, o próprio desenvolvimento sustentável, herança maior da proteção da pessoa humana no Estado Social, encontra-se em constante resiliência no âmbito do desenvolvimento socioeconômico. Não há como 
conceber, em dias atuais, apenas um aspecto simplista de uma solidariedade pontual, presente, mediata. A solidariedade que permeia o campo jurídico socioeconômico, que configura a razão de ser das políticas sociais e que se desdobra na concretização do desenvolvimento e no combate à pobreza, incorpora a sustentabilidade das gerações presente e futura, como meio eficaz da constante busca da efetivação da tutela jurídica dos direitos sociais (ROCHA, 2012).

É nesse contexto que a seguinte indagação ganha forças e proporções coerentes no mundo globalizado e moderno: "de quanta assistência ao desenvolvimento necessitam os países pobres?”.

\section{DE QUANTA ASSISTENNCIA AO DESENVOLVIMENTO ECONÔMICO NECESSITAM OS PAÍSES POBRES?A NOÇÃO DE CIDADANIA E OSDIREITOS AO/ DO DESENVOLVIMENTO}

Os países pobres necessitam de assistência quanto ao desenvolvimento socieoeconomico há muito tempo já evidenciado nos países considerados desenvolvidos, ou simplesmente, ricos. Não há, entretanto, como desassociar o desenvolvimento de um Estado da plenitude da cidadania nele vivenciado, posto que, conforme Hannah Arendt, a cidadania configura o direito a ter direitos, direitos estes que, sem dúvida, integram o rol dos direitos do/ao desenvolvimento, posto que, sem concretização da cidadania, a pobreza e a exclusão social não conseguem ser efetivamente combatidas e os países pobres não alavancam o salto que tanto necessitam para sair da pobreza e emergirem no desenvolvimento social, econômico e político.

A cidadania é uma condição da pessoa humana que se encontra no gozo do conjunto de direitos civis, políticos e sociais. Cumpre ressaltar que nesse contexto, os de ordem política consistem na "parte medular desses direitos, porque são os direitos que estabelecem o vínculo entre o particular e a sociedade estatalmente organizada". (SORTO, MAIA, 2009, p.97)

A pluralidade da ação, como condição humana de inserção no mundo político e, por conseguinte, da efetivação e plenitude da cidadania, necessita da preservação da liberdade e da manutenção do regime democrático. O pensamento Ariendtiano de que a liberdade só existe na democracia e a cidadania é pautada naquela é confirmado pelos pensadores modernos: 
Deve-se dar por assentado então que à cidadania é imprescindível a liberdade, que abunda nos Estados governados pelo Direito e que falta nos autoritários. A cidadania é, por este motivo, uma categoria político-jurídica de atribuição à pessoa humana de determinados direitos (civis, políticos e sociais) e também de deveres em face da comunidade à qual pertence. (ALÁEZ CORRAL, 2006, p.6)

Nesse contexto, cumpre ressaltar que o conceito de cidadania no Mundo Moderno é intrinsicamente relacionado aos Direitos Humanos, assumindo a roupagem de direito inato do ser humano. Na óptica Kantiana, (KANT, 2005) toda pessoa humana já nasce com direitos inatos, por esta razão, a cidadania assume laços estreitos com os direitos humanos no Mundo Moderno, passando a ter efetivação internacional; Hannah Arendt distingue Era Moderna de Mundo Moderno:

\begin{abstract}
A era moderna não coincide com mundo moderno. Cientificamente, a era moderna começou no séc. XVII e terminou no limiar do séc. XX; politicamente, o mundo moderno e que vivemos surgiu com as primeiras explosões atômicas. (ARENDT, 1983, p.13-14)
\end{abstract}

Os Direitos Humanos configuram herança maior da transição do Estado Liberal para o Estado Social; surgiram na tentativa de resolver uma profunda crise de desigualdade social que se instalou no mundo no período pós-guerra. A cidadania, como direito originador de outros direitos, reflete a real tentativa de tutela dos Direitos Humanos no Mundo Moderno, suscitando o pensamento jusnaturalista de Ernest Bloch, onde todos os direitos possuem sua origem na dignidade e no valor da pessoa humana. (2011).

É nesse sentido que a cidadania Arendtiana é concebida pautada na liberdade e na democracia, configurando-se como "o direito a ter direitos", visto que a cidadania abarca conjuntos de direitos que se apresentam como direitos de liberdade, quais sejam, os civis, políticos e sociais.

"A cidadania só é possível nos regimes que favoreçam a liberdade, tais como os democráticos. Visto que a liberdade é pressuposto para o exercício dos direitos que ela compreende." (SORTO, 2009, p.61) Na visão Arendtiana, não há como conceber cidadania sem liberdade e, por sua vez, não como preservar a liberdade em regimes que não sejam democráticos.

Nas palavras de Amartya Sen:

No campo da política, Rawls afirmou que a objetividade exige "uma estrutura pública de pensamento" que proporcione uma visão de concordância de julgamento entre agentes racionais. A racionalidade requer que os indivíduos 


\begin{abstract}
tenham a vontade política de ir além dos limites de seus próprios interesses específicos. Mas ela também impõe exigências sociais para ajudar um discernimento justo, inclusive o acesso a informação relevante, a oportunidade de ouvir pontos de vista variados e exposição a discussões e debates públicos abertos. Em sua busca de objetividade política, a democracia tem de tomar a forma de uma racionalidade pública construtiva e eficaz. (2010, p.54)
\end{abstract}

A cidadania, na concepção Arendtiana, requer a inserção do ser humano na comunidade política, essa inserção passa, sem dúvida, pela manifestação do discurso e da palavra. A ação política é realizada por palavras e no espaço público.

A violência por si só jamais pode ter grandeza, é o que fundamenta a expressão Arendtiana chamada de "banalidade do mal"; seria o mal praticado por ninguém, o mal que na verdade se exprime por meio de instrumentos lícitos de formas totalitárias. É a origem de todo o mal, que, sem o totalitarismo, nunca poderia ter sido conhecido.

Ora, "se podemos pensar por conta própria, só podemos agir em conjunto". Hannah Arendt se afasta da noção contemplativa do pensar e elege a ação como condição humana plural e capital da construção da cidadania, excluindo a mortalidade e elegendo a natalidade como "[...] categoria central de sua compreensão política. A natalidade também significa a esperança - a esperança que provém da natalidade [...]" Arendt visualiza na ação o signo da esperança que a natalidade enseja, qual seja, "a permanente e igualitária capacidade de começar algo novo.” (ARENDT, 1983, p.9)

É por meio da ação, fundada na acepção de natalidade, que nasce o conceito de cidadania Ariendtiano que converge no "direito a ter direitos"; a partir do momento que o ser humano nasce para a vida política e, através desse segundo nascimento, o nascimento original é confirmado e ele passa a exercer direitos e contrair obrigações na comunidade política, é que, segundo Hannah Arendt, nasce um cidadão.

Nesse contexto e em países como o Brasil, a exploração, a pobreza e a desigualdade geram o caldo da exclusão social e a consequente ineficácia do direito à cidadania. Necessário é, para a concretização do desenvolvimento e da cidadania e, consequentemente do combate à pobreza que macula a efetivação da cidadania, a execução de planos de ação para a redução da desigualdade e da pobreza, nas esferas econômica, social e política.

Importa nesse momento, ressaltar a diferença lecionada pela Prof. Maria Luiza Alencar Feitosa quanto ao Direito AO desenvolvimento, chamados de forma abreviada de "DaD" e do Direito DO desenvolvimento, os “DdD", tendo em vista que desenvolvimento é política e difere de crescimento econômico, que configura desempenho de mercado; cumpre ressaltar que a expressão "desenvolvimentismo" é o 
conjunto de ações econômicas, mais próximas às políticas nacionalistas, desembocando no crescimento econômico.

Direito econômico do desenvolvimento situa-se no âmbito das políticas públicas, internas ou internacionais, nos campos fiscal, trabalhista, de regulação econômica, dentre outros; direito humano ao desenvolvimento configura direitos de solidariedade, encarando o desenvolvimento para além de sua mera dimensão econômica ou de política econômica. (FEITOSA, 2013)

A tão necessária assistência ao desenvolvimento para os países pobres configura a necessária conjugação entre esses dois supracitados conjuntos conceituais. Nesse sentido, precisa, em caráter de urgência, ser realizado em prol do humano e em resgate das situações de vulnerabilidade, do contrário, não passará de objeto de retórica. (FEITOSA, 2013);

Os chamados Direitos ao desenvolvimento - $\mathrm{DaD}$ - propósitos mais protetivos do que promocionais, dialogam com os agentes sociais, se realizam materialmente não exatamente pela emissão de leis, mas pelo aprimoramento de políticas públicas e diretrizes programadas para a realização do desenvolvimento.

As Metas de Desenvolvimento do Milênio sumarizam a conjugação desses direitos, com a necessária compreensão de desenvolvimento como processo plural, além da roupagem econômica do termo. As MDMs configuram catálogo básico de orientação para adoção de medidas políticas e jurídicas que, amparadas quase sempre em medidas econômicas, podem servir de guia para a efetivação dos dois direitos - Dad e DdD.

A titularidade dos DdD abrange pessoas físicas, jurídicas e coletividades determinadas ou difusas, já nos $\mathrm{DaD}$, a titularidade abrange os seres humanos, povos e coletividades humanas. Nesse sentido, os sujeitos passivos de ambos se apresentam como sendo os Estados e as organizações internacionais de variada natureza. (FEITOSA, 2013)

Assistência ao desenvolvimento dos países pobres emerge em uma conjuntura integrada de ações coordenadas dos países ricos, bem como da colaboração dos pobres; passa, necessariamente, pela efetivação e concretização dos Dad e DdD por meio dasMetas de Desenvolvimento do Milênio, culminando em outra indagação inerente ao contexto estudado: Como seria um Pacto Global pelo direito ao desenvolvimento? 


\section{COMO SERIA UM PACTO GLOBAL PELO DIREITO AO DESENVOLVIMENTO ECONÔMICO SUSTENTÁVEL?A PARCERIAMUNDIAL NA BUSCA DO DESENVOLVIMENTO E DO COMBATE À POBREZA.}

Inicialmente cumpre destacar que, conforme Sachs, os países pobres devem levar a sério o fim da pobreza e efetivar a dedicação dos recursos nacionais para o combate à mesma, ao invés de investir em gastos com guerras, corrupção, disputas e políticas internas. (2005)

A possibilidade de combate à pobreza e a consequente efetivação do direito ao desenvolvimento deriva da necessária e urgente elaboração da Estratégia de Redução da Pobreza Baseada nas Metas de Desenvolvimento do Milênio, para que, o denominado "Teatro de sombras" - pobres fingem que fazem reformas; ricos fingem que ajudam possa ser efetivamente desarticulado e uma parceria entre oâmbito público e o privado, bem como um pacto global entre ricos e pobres possa de fato, ser efetivado e executado. (SACHS, 2005)

Defende Sachs que o contrato entre as partes - países pobres e ricos - deve gerar responsabilidade de ambos os lados;os países pobres não têm direito garantido de cumprir as MDMs ou receber assistência ao desenvolvimento dos países ricos, devem si, preocupar-se em gerir a ajuda e executar a boa governança. (2005)

Tendo em vista que Sachs é referência mundial no combate a pobreza e na militância de um pacto global pelo direito ao desenvolvimento, o referido doutrinador aponta para o conserto do "encanamento" da assistência internacional ao desenvolvimento para que seja eficaz na ajuda aos países bem governados. Nessa conjuntura, cada país de baixa renda deveria adotar uma estratégia de redução da pobreza (ERP), tendo em vista que a maioria atualmente a possui (elaboração com o FMI e o Banco Mundial). Nesse diapasão, percebe-se que, a plataforma de construção do sistema atual seria incoerente, por não contemplar uniformemente os seus signatários. 
As estratégias deveriam ser baseadas, conforme leciona Sachs, nas Metas de Desenvolvimento do Milênioe desdobrar-se em cinco partes: 1)diagnóstico diferencial; 2) plano de investimentos; 3 ) plano financeiro; 4)plano dos doadores; 5) plano da gestão pública. (2005)

Nesse contexto, os países pobres também emergem como possuidores de necessidades críticas que não podem ser resolvidas por investimentos nacionais ou regionais, ou por reforma da política interna, devem ser tratadas a nível global, não mais regional.

Diante de reformas globais, não mais regionais, entram em cena, na busca de um possível pacto global pelo direito ao desenvolvimento, os chamados parceiros de desenvolvimento - agências da ONU, doadores bilaterais e instituições de Bretton Woods - estes, configurando-se como parceiros, precisariam melhorar suas relações internas e internacionais, bem como tirar melhor proveito do sistema das nações unidas, através de uma ação integrada de coordenação dos doadores. (SACHS, 2005)

Nesse sentido, afirma Sachs sobre a dificuldade de determinar a quantia total de assistência ao desenvolvimento que o mundo pobre receberia do mundo rico e desenvolvido:

\begin{abstract}
"É complicado determinar a quantia total de assistência ao desenvolvimento que o mundo rico deveria fornecer ao pobre por três motivos: uma proporção considerável da assistência oficial não é de forma alguma para o desenvolvimento, mas para auxílios de emergência, refugiados, apoio geopolítico e ajuda a países de renda média; da porção de ajuda externa dirigida ao desenvolvimento, somente uma fração vem numa forma que pode ajudar a financiar o pacote de intervenções (ajuda nas dívidas); apoio de investimentos em nível global que estão acima e além das necessidades financeiras de países pobres específicos." (Sachs)
\end{abstract}

Numa conjuntura atual e otimista, percebe-se que os doadores do pacto global se resumem em:Japão (18\%); Alemanha, França, Itália e Reino Unido (20\%); EUA (51\%). Esses cálculos aferem as necessidades até 2015; após, conforme Sachs, as necessidades diminuiriam. "Quando chegarmos a 2015, a maior parte do mundo em desenvolvimento terá sido libertada da armadilha da pobreza e colocada na trilha do crescimento autosustentável.” (SACHS, p. 334, 2005)

Entretanto, cumpre ressaltar, por fim, que, mesmo diante de uma possível conjectura satisfatória de um pacto global pelo direito ao desenvolvimento dos países 
pobres, potencias mundiais como os Estados Unidos, por exemplo, encaram tal acordo como política compensatória somente, um mero favor aos países que, historicamente, devem ser ressarcidos, é o que se percebe do comportamento dos EUA diante da ajuda solicitada:

\begin{abstract}
A assistência ao desenvolvimento dos cidadãos americanos e do setor sem fins lucrativos compensa a deficiência de ajuda oficial; e mais, as remessas dos trabalhadores estrangeiros nos EUA para seus países de origem deveriam contar como forma de ajuda. Isso é ridículo [...] (SACHS, p. 350, 2005)
\end{abstract}

Enfim, percebe-se que mesmo diante de esforços internacionais, alguns países não comprometem-se como signatários fieis, de boa-fé e entusiastas do combate à pobreza; noutro norte, constata-se, felizmente, que países como o Canadá, dispõe de legislações de combate à pobreza e exclusão social, como a referente ao Estado do Quebeque, mesmo configurando-se como país rico na conjuntura internacional.

Esse contexto reflete na tão sonhada busca e efetivação do fim da pobreza, visto que, as políticas públicas sociais, os acordos internacionais, a execução de legi slações pontuais configuram como verdadeiros direitos anti-pobreza e consequentes direitos ao desenvolvimento.

\title{
CONSIDERAÇÕES FINAIS
}

A pobreza e a exclusão social são fenômenos que podem e devem ser combatidos, visto que ferem os direitos humanos na seara do direito ao desenvolvimento e, tornam-se obstáculos na concretização da cidadania.

A preocupação estatal na execução de políticas públicas anti-pobreza, desmembra-se do plano regional e ultrapassa fronteiras com a preocupação internacional em assistir os países pobres e em processo de desenvolvimento.

A teoria do subdesenvolvimento Furtadiana, permite observar que, historicamente, a exclusão social sempre foi alvo de preocupações estatais, sobretudo na transição do modelo econômico do Fordismo para o Toyotismo, entretanto, a preocupação com a pobreza e a crescente busca da efetivação do direito ao desenvolvimento são atuais.

Cada país de baixa renda deve adotar uma estratégia de redução da pobreza como instrumento da assistência internacional ao desenvolvimento, devendo as mesmas serem 
pautadas na Metas de Desenvolvimento do Milênio, contudo, mesmo diante de uma nova atmosfera de pacto internacional, complicado seria determinar a quantidade total de assistência ao desenvolvimento que o mundo rico deveria fornecer ao mundo pobre, isto porque, não se pode quantificar a real necessidade pontual de um país pobre possuindo como parâmetro de comparação os limites da pobreza, visto que, a sensação de exclusão social, bem como a própria exclusão social e a pobreza, possuem parâmetros de aferimento apartados e, consequentemente, o reflexo desses fenômenos são diferentes de

acordo com a conjuntura da pobreza em cada país.

Resta concluir que, a busca pela efetivação do direito ao desenvolvimento deve ser uma ação integrada entre os países ricos e os países pobres e que, os signatários desse acordo global, devem aumentar esforços na luta para a libertação da armadilha da pobreza e retomar a trilha do crescimento auto-sustentável inerente ao desenvolvimento como direito humano que o é.

\section{REFERÊNCIAS BIBLIOGRÁFICAS}

ARENDT, Hannah .A condição humana. $2^{\text {a }}$ ed. Trad. Roberto Raposo. Rio de Janeiro: Forense Universitária,1983.

DUPAS, Gilberto. Economia Global e Exclusão Social: Pobreza, Emprego, Estado e o Futuro do Capitalismo. $3^{\text {a }}$ ed. São Paulo: Paz e Terra, 2005.

, O Mito do progresso ou o progresso como ideologia. São Paulo: Unesp, 2006.

FEITOSA, Maria Luiza A. M; FRANCO, Fernanda; PETERKE, Sven; VENTURA, Victor A. M. F. Direitos humanos de solidariedade. Curitiba: Appris, 2013.

FEITOSA, Maria Luiza A. M. Exclusão social e pobreza nas interfaces entre o direito econômico do desenvolvimento e o direito humano ao desenvolvimento. In: Direito eDesenvolvimento no Brasil do Século XXI. Brasília: ipea, 2013.

FURTADO, Celso. Em busca de novo modelo: reflexões sobre a crise contemporânea. $2^{a}$ ed. São Paulo: Paz e Terra, 2002. 
FONSECA, João Bosco Leopoldino. Direito Econômico. São Paulo: Forense, 2012.

KANT, Immanuel. Sobre la paz perpetua. 7 ed. Trad. JoaquínAbellán. Madrid: Tecnos, 2005.

MESTRINER, Maria Luiza. O Estado entre a filantropia e a Assistência Social. São Paulo: Cortez, 2001.

ROCHA, Joaquim Freitas. Sustentabilidade e finanças públicas responsáveis. Urgência de um direito financeiro equigeracional. p.619-639. In: CORREIA, Fernando Alves, LOUREIRO, João Carlos Loureiro e MACHADO, Jonatas E. M. (orgs). Estudos emhomenagem ao prof. Doutor José Joaquim Gomes Canotilho. Coimbra: CoimbraEditora, 2012.

SACHS, Jeffrey D. O fim da pobreza: como acabar com a miséria mundial nos próximos vinte anos. São Paulo: Companhia das letra, 2005.

SEN, Amartya; KLIKSBERG, Bernardo. As pessoas em primeiro lugar: a ética do desenvolvimento e os problemas do mundo globalizado. São Paulo: Companhia das Letras, 2010.

SORTO, Fredys Orlando; MAIA, Mário Sérgio Falcão. Cidadania, direitos sociais e indivisibilidade dos direitos humanos. In: LEAL, Mônica Clarissa Henning (org.)

Trabalho, constituição e cidadania: reflexões acerca do papel do constitucionalismo na ordem democrática. Porto Alegre: Verbo Jurídico, 2009, p. 97-108.

SPOSATI, Aldaíza: A menina LOAS: um processo de construção da AssistênciaSocial. $2^{\circ}$ ed. São Paulo: Cortez, 2005.

TRINDADE, Antônio Augusto Cançado. Tratado de direito internacional dos direitos humanos. Vol. II. Porto Alegre: Sergio Antonio Fabris Editor, 1999. 
